\title{
Oral L-Arginine Supplementation Effects on Cardiometabolic Factors in Hypertensive Patients with Rheumatoid Arthritis and its Relationship with Body Mass Index
}

\author{
Olexandr Kuryata* and Oksana Sirenko
}

\begin{abstract}
State Establishment, Dnipropetrovsk Medical Academy of Health Ministry of Ukraine, Department of Hospital Therapy \#1 and Occupational Diseases, Dzerzhynskogo str. 9, 49044, Dnipropetrovsk, Ukraine
\end{abstract}

\begin{abstract}
Hypertension and rheumatoid arthritis are regarded as a conditions associated with higher risk for cardiovascular disease. As known endothelial dysfunction is an early pathophysiological feature and an independent predictor cardiovascular disease. L-arginine is the amino acid with potential to improve endothelial function and is expected to play a role in the prevention or treatment of cardiovascular disease. In addition, data exists that L-arginine aspartate can reduce insulin resistance. We aimed to evaluate the effects of oral L-arginine supplementation on cardiometabolic factors by determining endothelial function, insulin resistance, adiponectin level in hypertensive patients combined with rheumatoid arthritis and its relationship with body mass index. 69 females with mean age - 54 [50,3; 61,5] years were enrolled. The $1^{\text {st }}$ group made up 29 patients with hypertension combined with rheumatoid arthritis, $2^{\text {nd }}$ group - 20 patients with rheumatoid arthritis, $3^{\text {rd }}$ group -20 patients with hypertension. In the endpoint patients were randomized to study subgroups patients, which received L-Arginine aspartate $30 \mathrm{ml} /$ day during 4 weeks in addition to standard treatment, and control subgroups - received only the standard treatment. The levels of total cholesterol, triglycerides, C-reactive protein, serum creatinine, body mass index, body area index were determined. Insulin resistance, adiponectin level, endothelial-dependent flow mediated vasodilatation of brachial artery were measured at baseline and after 4 weeks. In patients with hypertension combined with rheumatoid arthritis identified a significant increase in insulin levels, insulin resistance, adiponectin, which were associated with cardiovascular risk, abdominal obesity, inflammatory activity levels. Oral supplementation of L-arginine causes multiple beneficial effects on the complex of cardiometabolic factors including: endothelial dysfunction, peripheral insulin resistance, adiponectin level in hypertensive patients with rheumatoid arthritis, mainly in obesity case. With the correction of endothelial function were established more significantly changes in the investigated parameters.
\end{abstract}

Keywords: L-arginine, endothelial dysfunction, insulin resistance, adiponectin, obesity.

\section{INTRODUCTION}

Improvements in rheumatoid arthritis (RA) treatments have resulted in increases in median life expectancy for this persons. Older RA patients now face the same medical conditions associated with aging in the general population, including cardiovascular disease (CVD) [1]. On the other hand, RA should be regarded as a condition associated with higher risk for $\mathrm{CV}$ disease and the key feature explaining this increased $\mathrm{CV}$ risk seems to be inflammation [2, 17]. Therefore, experts EULAR in 2010 published recommendations for management of patients with cardiovascular risk in RA [2].

Hypertension $(\mathrm{HT})$ is quantitatively the most important modifiable risk factor for CVD seems highly prevalent in RA. The frequency of hypertension in RA varies from 18 to $70.5 \%$ according to different data [3]. It was noted in RA patients frequent $(46 \%)$ and early formation of isolated systolic HT [4, 5], the most unfavorable in terms of cardiovascular complications,

*Address correspondence to this author at the State Establishment, Dnipropetrovsk Medical Academy of Health Ministry of Ukraine, Department of Hospital Therapy \#1 and Occupational Diseases, Dzerzhynskogo str. 9, 49044, Dnipropetrovsk, Ukraine; Tel: +3 8056 713-53-34; Fax: +3 8056 713-53-34;

E-mail: gt1@dsma.dp.ua which is higher than prevalence in general population [6]. According to these facts cardiovascular risk management in HT patients combined with RA seems to be important for the fatal cardiovascular events prevention. Limited predictive value of traditional factors in HT patients in combination with RA, and the inconsistency of their impact, complexity of verification of atherosclerotic vascular lesions in RA necessitates the introduction into clinical practice of additional markers of cardiovascular risk and finding ways to influence them [7].

The cardiometabolic syndrome, an interesting constellation of cardiovascular, renal, metabolic, prothrombotic, and inflammatory abnormalities, widely discussed in the recent literature. Co-morbidities common in RA, such as insulin resistance, dyslipidaemia, adipose tissue metabolic disorders and obesity $[8,9,18]$ have been shown to associate with essential HT and cardiometabolic syndrome in the general population $[10,19]$. Obesity is highly prevalent in RA especially abdominal obesity. It is now recognized that adipose tissue is dynamic and metabolically active organ that secretes a number of bioactive molecules called adipokines [11], which may play a role in the development of atherogenesis in 
patients with RA [12]. A special role in cardiometabolic continuum, including in RA patients is given to adiponectin, positioned as an additional marker of cardiovascular risk [12]. However, it is unknown whether RA changes the influence of adipokines on cardiovascular metabolic risk [13].

Endothelial dysfunction is highly prevalent in RA [24] and considered as a link between cardiometabolic factors leading to the initial stage of cardiovascular continuum [15, 22]. Endothelial dysfunction initiates early atherogenesis and contributes to the development of clinical features in the later stages of the vascular disease including progression of the atherosclerotic plaque [28]. Endothelial dysfunction may be determined as an impaired ability of the artery to dilate in response to physical and chemical stimuli due to a decreased released or increased breakdown of NO [29]. This impaired NO bioavailability and RA disease-related inflammation leads to impairment in endothelium dependent vasodilatation in this patients [30]. These facts causes the search for ways of endothelial dysfunction correction in HT patients with RA [24]. L-arginine is a nutritionally important amino acid that have a wide spectrum of functions in various metabolic processes. L-arginine is a precursor for nitric oxide (NO), and thus takes part in regulation of endothelial function [14, 21]. In addition, Dong et al. in meta-analysis demonstrated that L-arginine aspartate can reduce insulin resistance. Considering these properties it may be beneficial L-arginine aspartate using in HT patients with RA. We aimed to evaluate the effects of oral l-arginine supplementation on cardiometabolic factors by determining endothelial function, insulin resistance, adiponectin level in hypertensive patients combined with RA and its relationship with body mass index.

\section{PATIENTS AND METHODS}

\subsection{Patients}

The present study was conducted with approval from the Ethics Committee at State Establishment «Dnipropetrovsk Medical Academy of Health Ministry of Ukraine» according to the principles outlined in the Helsinki declaration.

All participants of research gave informed, written consent. 69 females from 45 to 65 years with established diagnosis of HT according to 2013 ESC Guidelines and RA according to the 1988 American College of Rheumatology and 2010 American College of Rheumatology/EULAR criteria for RA were enrolled. Only female subjects were selected considering the gender structure of RA. All patients received stable therapy of rheumatoid arthritis more than 6 months. Patients with verified diagnosis of ischemic heart disease and diabetes mellitus haven't included in the study. Antihypertensive treatment received 42 (72.4\%) of HT patients: ACE inhibitors - $30(71.4 \%)$ patients, angiotensin II receptor antagonist - $11(26.2 \%)$, bblockers - 8 (19.0\%), diuretics - 15 (35.7\%). Statins received $30(43.5 \%)$ enrolled patients. Basic diseasemodifying RA treatment received $50(80.6 \%)$ patients: methotrexate - $40(80.0 \%)$ patients, leflunomide - 8 $(16.0 \%)$, sulfasalazine $-2(4.0 \%)$, the average dose of methotrexate was $15[10 ; 15] \mathrm{mg}$ per week, the average duration of treatment with methotrexate 66 [48; 90] months. Glucocorticoids received 39 patients $(67.2 \%)$, the average daily dose of methylprednisolone was $6[4 ; 6] \mathrm{mg}$, the mean duration of glucocorticoid therapy - 60 [30; 93] months.

\subsection{Assessments}

Height, weight, and waist and hip circumference were measured using standard approaches. Overall adiposity, abdominal obesity, and fat distribution were estimated by the body mass index (BMI), waist circumference, and waist-hip ratio, respectively. We assessed systolic blood pressure (SBP), diastolic blood pressure (DBP), disease activity for RA by the Disease Activity Score for 28 joints based on erythrocyte sedimentation rate (DAS28-ESR). C-reactive protein concentrations were determined using immunoturbidimetric methods. Standard laboratory blood tests of erythrocyte sedimentation rate, renal and liver function, hematological parameters, lipids, and glucose were performed. The glomerular filtration rate was estimated using the CKD-EPI formula. Cardiovascular risk was assessed by SCORE models adapted for patients with RA by introducing a 1.5 multiplication factor and total cholesterol/HDL cholesterol ratio according to EULAR evidence-based recommendations for cardiovascular risk management in patients with rheumatoid arthritis and other forms of inflammatory arthritis.

Insulin and adiponectin concentrations were measured at the baseline and after 4 weeks using solid-phase sandwich enzyme-linked immunosorbent assays (ELISA) (DRG, Germany and ASSAYPRO, USA respectively). Normal adiponectin concentration in blood serum was considered 3-14 ng/mL, insulin - 2 $25 \mu \mathrm{lU} / \mathrm{mL}$. The level of insulin resistance, function of 
pancreas cells, peripheral tissue sensitivity to insulin index were calculated using the standard formula HOMA1 (E. Bonora, 1998), HOMA2 (Wallace T, 2004) using HOMA 2 Calculator Version 2.2.2. HOMA1-IR values above 2.77 and HOMA2-IR above 1.00 testified insulin resistance. Using both indices HOMA1, HOMA2 was due to the lack of clear guidance of the insulin resistance model using in patients with HT with RA. Determination of flow mediated vasodilation of brachial artery was performed at the baseline and after 4 weeks based on Celermajer's recommendation (1992). The diameter of the brachial artery was measured with 7.5 $\mathrm{MHz}$ transducer of «Philips Envisor C».

\subsection{Study Design}

In the endpoint patients were prospectively randomly and blindly divided into study group patients, which received L-Arginine aspartate (Tivortin, "YuriyaFarm", Kiev, Ukraine) in an oral solution $30 \mathrm{ml} /$ day during 4 weeks (average period evaluating the effectiveness according to the literature) in addition to standard treatment, and control group - received only the standard treatment. Patients also were devided into three groups depending on HT and RA comorbidity to study cardiometabolic risk features in combining of these nosology. The $1^{\text {st }}$ group made up 29 patients with hypertension combined with rheumatoid arthritis, $2^{\text {nd }}$ group - 20 patients with rheumatoid arthritis, $3^{\text {rd }}$ group - 20 patients with hypertension. All groups have been matched by age, disease duration, received therapy.

\subsection{Statistical Analysis}

Statistical computations were made using the Statistica program v. 6.1. (StatSoft Inc.), and «Excel 2013» (Microsoft). Data are shown as number of subjects (\%) or median (interquartile range [IQR]) because data were not normal distribution. The Mann - Whitney U-test and Wilcoxon test were used to analyze differences between two independent and dependent groups respectively. Correlation coefficient Spearmen $(R)$ was calculated. A $p$ value $<0.05$ was considered statistically significant.

\section{RESULTS}

\subsection{Patient Characteristics}

Baseline characteristics in study patients are given in Table 1. In the HT+RA group in compare with RA group there were significant higer BMI $(p<0.001)$, waist circumference $(p<0.001)$ waist-hip ratio $(p<0.001)$ wherein this group of patients were more often obesity $(p<0.001)$. BMI was highly correlated in hypertensive RA patients with GFR $(R=0.38(p<0.05)$, duration of glucocorticoids therapy $(R=0.50(p<0.05)$, insulin level $(R=0.40(p<0.05)$ and insulin resistance matched by HOMA-1 and HOMA-2 models $(R=0.47(p<0.05), R=$ $0.44(p<0.05)$, respectively).

HT patients with RA characterized by significant 5 times higer SCORE level in compare with RA group $(p=0.02)$. Analyzing cardiometabolic factors has been

Table 1: Baseline Characteristics in Stydied Patients

\begin{tabular}{|c|c|c|c|}
\hline Characteristics & $\begin{array}{l}\text { Hypertension+Rheumatoid arthritis } \\
\qquad(n=42)\end{array}$ & $\begin{array}{l}\text { Rheumatoid arthritis } \\
\qquad(n=20)\end{array}$ & $\begin{array}{l}\text { Hypertension } \\
(n=20)\end{array}$ \\
\hline \multicolumn{4}{|l|}{ Baseline characteristic } \\
\hline Smoking (\%) & 23,8 & 25 & 20 \\
\hline Body mass index, $\mathrm{kg} / \mathrm{m} 2$ & $28,1[26,0 ; 33,1]$ & $24,1[22,4 ; 26,2]^{\star *}$ & 28,2 [25,6;32,0]@ \\
\hline Waist-hip ratio & $0,97[0,89 ; 1,02]$ & $0,85[0,75 ; 0,91]^{\star *}$ & 0,89 [0,86;0,93]@ \\
\hline RA duration, years & $7[3 ; 10]$ & $7[2,3 ; 11,5]$ & - \\
\hline HT duration, years & $8[5 ; 10]$ & - & $10[5 ; 10]$ \\
\hline Rheumatoid factor positive (\%) & 83,3 & 80 & - \\
\hline
\end{tabular}

*significant differences between the main group and the comparison group A $p<0.05$ (by Mann-Whitney test) ${ }^{* *} p<0.001$. \#significant differences between the main group and the comparison group $B p<0.05$ (by Mann-Whitney test) \#\# $p<0.001$. $@$ - significance of differences between comparison groups $p<0.05$ (by Mann-Whitney test). 
established that HT patients with RA had significant higer triglycerides level, LDL cholesterol level, but not in their cholesterol-HDL and total cholesterol level. Cholesterol-HDL cholesterol ratios had a tendency to increase in HT patients with RA.

Endothelial function measured by EDVD was significantly lower among the HT patient with RA. It should be noted, that vasoconstriction and lack of EDVD dynamics were recorded only among HT patients with RA group. Significant correlation have been established between EDVD level and of DAS28 $(R=-0.68, p<0.05)$, SCORE level $(R=-0,65, p<0.001)$, waist circumference $(R=0.48, p<0.05)$, GFR $(R=0,58$, $\mathrm{p}<0.05)$.

Table 2 shows that as compared to HT, RA groups there was significantly higher adiponectin, insulin, insulin resistance levels among HT+RA group patients. It should be noted that increased adiponectin level wasn't estimated among isolated HT patients.
Adiponectin level was correlated with waist-hip ratio $(R=0.48, p<0.05)$, DAS28 $(R=0,48, p<0.05)$, SCORE level $(R=0,46, p<0.05)$, rheumatoid factor concentration $(R=0,43, p<0.05)$ and inversely correlated with $G F R$ $(R=-0,48, p<0.05)$, EDVD $(R=0,44, p<0.05)$. HOMA1$2 \mathrm{R}$ level was correlated with waist circumference $(R=0.48, p<0.05)$, DAS28 $(R=0.36, p<0.05)$, EDVD $(R=-0.43, \quad p<0.05), \quad$ GFR $\quad(R=-0.34, \quad p<0.05) \quad$ and association with adiponectin level $(R=0,27, p<0,05)$. According to our data use of the model HOMA2-IR, perhaps more fully reflects the presence of insulin resistance and its association to patients with hypertension combined with RA. Data demonstrates increased functional activity of the pancreas insular part, and significant decrease in peripheral insulin receptors sensitivity in HT+RA group patients.

After 4 weeks of treatment with L-Arginine mean EDVD was increased by $23.2 \%$ on the whole $(p<0.001)$, in compare with standard therapy - on $20.2 \% \quad(p=0.03)$. Paradoxical vasoconstriction was

Table 2: Cardiometabolic Risk Factors in Study Patients Depending on Comorbidity Hypertension and Rheumatoid Arthritis

\begin{tabular}{|c|c|c|c|}
\hline Cardiometabolic risk factors & $\begin{array}{l}\text { Hypertension+ } \\
\text { Rheumatoid arthritis } \\
(n=29)\end{array}$ & $\begin{array}{l}\text { Rheumatoid arthritis } \\
\qquad(n=20)\end{array}$ & $\begin{array}{l}\text { Hypertension } \\
\qquad(n=20)\end{array}$ \\
\hline Diastolic blood pressure, $\mathrm{mmHG}$ & $78,0[74,1 ; 83,4]$ & $70,0[68,4 ; 73,1]^{*}$ & $80,2[72,9 ; 84,8]$ \\
\hline mSCORE, \% & $4[1,0 ; 5,5]$ & $0,8[0,7 ; 1,4]^{*}$ & $1,9[1,6 ; 5,8]$ \\
\hline Total cholesterol, $\mathrm{mmol} / \mathrm{l}$ & $6,1[4,8 ; 6,7]$ & $5,0[4,2 ; 5,9]$ & $5,3[4,7 ; 6,2]$ \\
\hline HDL cholesterol, mmol/l & $1,3[0,9 ; 1,6]$ & $1,3[1,1 ; 1,6]$ & $1,3[1,0 ; 1,4]$ \\
\hline Cholesterol-HDL cholesterol ratio & $4,4[3,4 ; 6,1]$ & $3,7[2,9 ; 4,6]$ & $3,8[3,0 ; 5,9]$ \\
\hline LDL cholesterol, mmol/l & $4,8[3,4 ; 5,4]$ & $3,8[3,0 ; 4,7]$ & $3,24[2,8 ; 4,5] \#$ \\
\hline Adiponectin, ng/ml & $13,4[12,5 ; 14,8]$ & $13,1[8,4 ; 14,3]^{\star *}$ & $11,2[10,5 ; 11,9] \# \#$ \\
\hline Insulin, $\mu \mathrm{IU} / \mathrm{mL}$ & $14,0[11,8 ; 21,5]$ & $11,5[9,8 ; 15,1]^{*}$ & $11,2[7,9 ; 14,8] \#$ \\
\hline HOMA1-IR & $3,3[2,6 ; 5,5]$ & $2,7[2,1 ; 3,6]^{*}$ & $2,5[2,0 ; 3,5] \#$ \\
\hline HOMA1-IR>2.77 (\%) & 59.5 & $35^{\star *}$ & $45 \#$ \\
\hline HOMA2-IR & $1,8[1,5 ; 2,8]$ & $1,4[1,2 ; 2,0]^{*}$ & $1,4[1,1 ; 1,9] \#$ \\
\hline HOMA2-IR>1.00 (\%) & 83.3 & $50^{* *}$ & $60 \#$ \\
\hline HOMA2-\%B & $140,1[111,6 ; 184,1]$ & $125,0[99,4 ; 155,6]$ & $110,0[92,3 ; 134,8] \#$ \\
\hline
\end{tabular}

*significant differences between the main group and the comparison group A $p<0.05$ (by Mann-Whitney test) ${ }^{* *} p<0.001$.

\#significant differences between the main group and the comparison group B $p<0.05$ (by Mann-Whitney test) \#\# $p<0.001$

@ - significance of differences between comparison groups $p<0.05$ (by Mann-Whitney test). 
corrected in all patients. Endothelial function normalizing was achieved in $25(65.8 \%)$ of L-Arginine group of patients, i.e. the number of patients with a normal level of EDVD was increased by $34.2 \%$ in this group, that significantly higer than in standart therapy group $(p<0.001)$. Table 4 shows after 4 weeks of LArginine aspartate supplementation EDVD was significantly higer than in standart therapy group $(p<0.001)$. The level of EDVD to end of the observation in the study subgroups was $10.7[10.3 ; 11.0] \%$ in HT patients with RA, $9.2[9.1 ; 10.5] \%$ in RA patients, 9.7 [9.5; 10.7] \% in HT patients, i.e. EDVD was increased in this groups on $58.5 \%(p=0.003), 17.4 \% \quad(p=0.03)$, $13.4 \% \quad(p=0.04)$ respectlively. Preferential increase number of patients with a normal level of EDVD was observed in HT patient with RA - on $33.6 \%(p<0.001)$, in RA patients - on $5.4 \%(p=0.05)$, in HT patients - on $4.8 \%(p=0.07)$. It should be noted, that in HT patients with RA was maximal number of patients with corrected endothelial function - $12(80.0 \%)$, in RA group - 5 (45.5\%), in HT group - 7 (58.3\%).

The level of insulin to the end of the study was lower on $9.3 \%(p=0.004)$, insulin resistance - on $7.9 \%$ $(p=0.004)$ matched by HOMA1-IR and on $18.7 \%$ $(p=0.002)$ matched by HOMA2-IR among patients received L-Arginine aspartate. Thus the insulin resistance correction in this patients was mainly due to increase the sensitivity of insulin receptors, as evidenced by the dynamics of indicators HOMA2-\%B, HOMA2- $\% S--4.3 \%(p=0,003)$ and $+15.5 \%(p<0,001)$ respectively (Table 4 ). In the standard treatment group these parameters in the dynamics weren't differ significantly. The level of insulin resistance matched by HOMA1-IR, HOMA2-IR to end of the observation in the study subgroups was respectively $3.0[2.6 ; 3.6], 1.3$ [1.0; 1.8] in HT patients with RA, 2.6 [2.2; 3.2], 1.3 [1.1; $1.8]$ in RA patients, 2.3 [2.0; 2.8], $1.2[1.0 ; 1.7]$ in HT patients. Thus pronounced dynamics of reducing insulin resistance was observed by index HOMA2-IR in HT patients with RA - reducing by $22.8 \%(p=0.001)$ (Figure 1). Should be noted tends to reduce the level of adiponectin in patients received L-arginine aspartate $(p=0.06)$, wherein maximal dynamic observed in HT patients with RA - on $4.2 \%(p=0.06)$ (Figure 1$)$.

After 4 weeks of L-Arginine aspartate supplementation in study subgroups obesity patients established significantly higer insulin resistance reducing dynamic matched by HOMA1-IR, HOMA2-IR compare to non-obesity patients. Thus, to the end of the study in study subgroups obesity patients HOMA1IR, HOMA2-IR decreased from 4.6 [4.5; 4.9], 2.7 [2.5;
$2.9]$ to $4.3[4.0 ; 4.5], 2.3[2.1 ; 2.5]$ respectively $(p=0.01$, $\mathrm{p}=0.003)$, in non-obesity patients - from 2.8 [2.6; 3.5], $1.6[1.2 ; 1.9]$ to $2.7[2.5 ; 3.4], 1.4[1.2 ; 1.7]$ respectively $(p=0.7, p=0.4)$. No changes in other parameters studied were observed. The inclusion of L-arginine aspartate contributed to the most significant increase HOMA2-\%S on reaching EDVD $\geq 10 \%$ - on $32.8 \%$ compare to patients with EDVD $<10 \%$ (Table 3). In patients with endothelial dysfunction correction observed a significant decrease of adiponectin in compare to preserved endothelial dysfunction patients on $11.2 \%(p=0.04)$.

\section{DISCUSSION}

As known in the pathogenesis of accelerated atherosclerosis in RA a major issue is the development of endothelial activation, which leads to endothelial dysfunction a premature atherosclerosis in these patients [31]. Increased levels of circulating inflammatory mediators might cause activation and damage of endothelial cells in patients with RA that leads to decreasing of NO formed from the amino acid L-arginin [32]. Endothelial derived NO participates in several atheroprotective functions such as relaxing vascular smooth muscle cells, inhibition of platelet and leukocyte adhesion to vascular endothelium, inhibition of the vascular smooth muscle cell migration and growth, and limiting the oxidation of atherogenic low density lipoproteins in addition to its effect on vessel tone and blood pressure [33, 34]. Reduced bioavailability of $\mathrm{NO}$ is considered the key feature of endothelial dysfunction in $\mathrm{HT}$ also. HT and RA combination appears to have a complex association with endothelial dysfunction, a phenotypical alteration of the vascular endothelium that precedes the development of adverse cardiovascular events and portends future cardiovascular risk [22].

Cause-and-effect relationship of endothelial dysfunction and insulin resistance are debated. Many studies have shown that endotelial dysfunction is a consequence of the mechanisms underlying the insulin resistance - hyperglycemia, HT, dyslipidemia [28].Without a doubt, insulin resistance and endotelial dysfunction are closely linked and form abnormal "vicious circle". Despite still uncertainty causal relationships in the pathogenesis of endotelial dysfunction, it is indisputable that it's the first step in the development of atherosclerosis, which is associated with the insulin resistance. Therefore, further study of endothelial dysfunction and methods of its correction is implicitly relevant. 

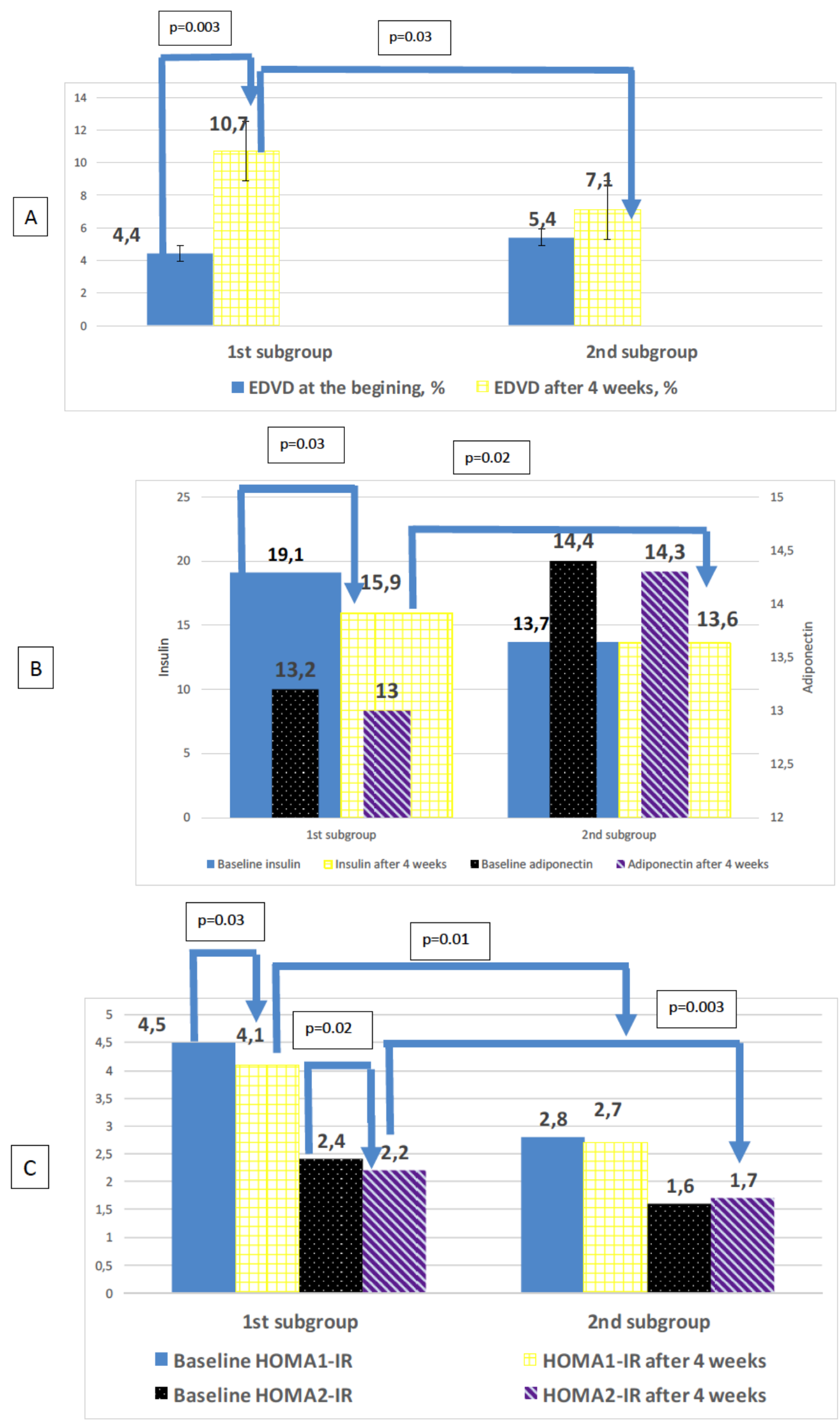

Figure 1: Dynamics levels of endothelium dependent vasodilatation (A), adiponectin, insulin (B), insulin resistance (C) after 4 weeks in hypertensive patients with rheumatoid arthritis. 
Table 3: The Levels of Adiponectin, Insulin, Insulin Resistance Depending on the Degree of Endothelial Function Correction

\begin{tabular}{|c|c|c|c|}
\hline & $\begin{array}{l}\text { EDVD after } 4 \text { weeks } \geq 10 \% \\
n=35\end{array}$ & $\begin{array}{l}\text { EDVD after } 4 \text { weeks }<10 \% \\
n=34\end{array}$ & $\mathbf{P}$ \\
\hline Adiponectin, ng/ml & $12,7[11,8 ; 13,8]$ & $14,3[13,1 ; 15,3]$ & 0,04 \\
\hline HOMA1-IR & $2,7[2,6 ; 4,2]$ & $4,3[3,8 ; 5,2]$ & 0,07 \\
\hline HOMA2-IR & $1,5[1,3 ; 1,9]$ & $2,3[2,0 ; 2,6]$ & 0,04 \\
\hline HOMA2-\%S & $58,0[38,5 ; 64,0]$ & $39,0[27,5 ; 42,0]$ & 0,02 \\
\hline
\end{tabular}

Table 4: Dynamics Endothelium Dependent Vasodilatation (EDVD), Adiponectin, Insulin, Insulin Resistance Levels after 4 Weeks in Study Patients

\begin{tabular}{|c|c|c|c|c|}
\hline \multirow{2}{*}{$\begin{array}{c}\text { Cardiometabolic } \\
\text { risk factors }\end{array}$} & \multicolumn{3}{|c|}{$\begin{array}{c}\text { Study patients } \\
\text { (n=69) }\end{array}$} \\
\cline { 2 - 5 } & \multicolumn{2}{|c|}{ +L-Arginine aspartate } \\
(n=38) & After 4 weeks & Baseline & Standart treatment \\
(n=31)
\end{tabular}

*significant differences between groups in dynamics $p<0.05$ (by Wilcoxon test) ${ }^{* *} p<0.001$.

\# - significant differences between the L-Arginine aspartate group and the standart treatment. group $\mathrm{p}<0.05$ (by Mann-Whitney test).

Current data support a complex relationship of endothelial dysfunction and cardiometabolic factors in HT, RA presence. According to our data, endothelial function was significantly lower in comorbidity of HT and RA and was associated mainly with abdominal obesity, inflammation activity and renal function. Perhaps this may indicate a relationship with metabolic factors such as the adipose tissue exchange. Thus, as endothelial dysfunction is one of the early stages of atherosclerosis, it is reasonable to consider that substances secreted by adipose tissue may influence directly or indirectly (for instance by induction of microinflammation) the function of endothelial cells. Inflammation in adipose tissue, apparent in visceral fat depots, is associated with impaired endothelial function in obese patients [21]. On the other hand RA characterized by high prevelance of obesity and endothelial dysfunction in the development plays an important role contradictory impact medication of RA. To understand the cardiometabolic abnormalities features in present study, the differences between groups divided according to the comorbidity of $\mathrm{HT}$ and RA may form the certain conclusions. HT patients with RA presents significant higer prevalence of abdominal obesity, endothelial dysfunction, dyslipidemia, insulin resistance, adipose tissue metabolic disturbance that needs correction. 
The main message of the present study is that the correction and expectly normalizing of endothelial dysfunction in HT patients with RA with L-Arginine aspartate supplementation may caused benefit effects on range of cardiometabolic factors. Current obtained data may indicate the key role of endothelial function in reducing the sensitivity of peripheral insulin receptors and adiposity dysfunction in HT patients with RA, which requires more detailed study. As such, assessments of endothelial function on example of L-Arginine aspartate supplimentation could prove to be useful tools in the identification and monitoring of cardiometabolic risk in HT patients with RA. It should be noted that the increase in insulin sensitivity under the influence of Larginine is also noted in other studies. Thus, R. Lucotti et al. [26] in a randomized, double-blind study involving 64 patients with CVD without diabetes after coronary artery grafting bypass orally for 6 months L-arginine at a dose of $6.4 \mathrm{~g} /$ day, established EDVD increase $(p<0.01)$, decrease in insulin resistance $(p<0.05)$ and increased adiponectin levels ( $p<0.01)$. In a study conducted Piatti P M. et al. oral administration of 9 grams/day of L-arginine for 1 month in patients with type 2 diabetes has led to a significant increase in forearm blood flow (36\%), normalization initially reduced cGMP level, decrease in systolic blood pressure by $14 \%$ and improved sensitivity to insulin [27]. In 2011 Dong, J.Y. et al. published meta-analysis of 11 randomized, double-blind, placebo-controlled trials used oral L-arginine supplementation showed possible insulin resistance reducing effect [16]

Including L-Arginine aspartat in complex therapy in HT patients with RA appear to have added benefits with respect to endothelial function, but whether these benefits translate into improved outcomes remains unknown. Answers to these questions gained through future investigations may give us the knowledge to develop and implement novel interventions and strategies to reduce the morbidity and mortality of HT patients with RA. The dynamics EDVD increase, decrease HOMA index may indicate confirmation that endothelial dysfunction is the "cornerstone" of not only HT patients with RA progression, but also the development of metabolic changes that accompany it.

\section{LIMITATIONS}

However, the results of this study should be interpreted with caution because of several limitations. Therefore, only female subjects were chosen for this study, and consequently the results can only be applied to the female gender. The study was carried out in a 4- weeks period, and as that time was not enough for adequate evaluation of hard end points, such as insulin resistance and adiponectin normalisation, the study assesses only intermediate end points. However, it cannot be established from the present study whether the changes observed were permanent or reversible. In this regard, more prolonged L-arginine supplimentation study in hypertensive patients with rheumatoid arthritis requires.

\section{CONCLUSIONS}

1. In hypertensive patients with rheumatoid arthritis identified a significant increase of insulin levels, insulin resistance, adiponectin, which were associated with cardiovascular risk, abdominal obesity, inflammatory activity.

2. Oral supplementation of L-arginine causes multiple beneficial effects on the complex of cardiometabolic factors including: endothelial dysfunction, peripheral insulin resistance, adipose tissue exchange in hypertensive patients with rheumatoid arthritis, mainly in obesity case. With the correction of endothelial function were established more significantly changes in the investigated parameters.

\section{REFERENSES}

[1] Naranjo A, Sokka T, Descalzo MA, et al. Cardiovascular disease in patients with rheumatoid arthritis: results from the QUEST-RA study. Arthritis Research Therapy 2008; 10(2): R30.

http://dx.doi.org/10.1186/ar2383

[2] Peters MJ, Symmons DP, McCarey D. EULAR evidencebased recommendations for cardiovascular risk management in patients with rheumatoid arthritis and other forms of inflammatory arthritis. Annals of the Rheumatic Diseases 2010; 69: 325-331 http://dx.doi.org/10.1136/ard.2009.113696

[3] Panoulas VF, Douglas KM, Milionis HJ, StavropoulosKalinglou A, Nightingale P, Kita MD, Tselios AL, Metsios GS, Elisaf MS, Kitas GD. Prevalence and associations of hypertension and its control in patients with rheumatoid arthritis. Rheumatology 2007; 46(9): 1477-1482. http://dx.doi.org/10.1093/rheumatology/kem169

[4] Panoulas VF, Metsios GS, Pace AV, John H, Treharne GJ, Banks MJ, Kitas GD. Hypertension in rheumatoid arthritis Rheumatology 2008; 47: 1286-1298. http://dx.doi.org/10.1093/rheumatology/ken159

[5] Singh G, Miller JD, Huse DM, Pettitt D, D'Agostino RB Russell MW. Consequences of increased systolic blood pressure in patients with osteoarthritis. J Rheumatol April 2003; 30(4): 714-719.

[6] Protogerou AD, Panagiotakos DB, Zampeli E, Argyris AA Arida K, Konstantonis GD, Pitsavos C. Arterial hypertension assessed "out-of-office" in a contemporary cohort of rheumatoid arthritis patients free of cardiovascular disease is characterized by high prevalence, low awareness, poor control and increased vascular damage-associated "white 
coat" phenomenon. Arthritis Research \& Therapy 2013; 15: 142-146.

http://dx.doi.org/10.1186/ar4324

[7] Kuryata $O$, Sirenko $O$. Subclinical manifestations of atherosclerosis, the functional state of the endothelium and vascular stiffness in hypertensive patients with rheumatoid arthritis. Actual problems of modern medicine: Bulletin of Ukrainian Medical Stomatological Academy 2014; 14 № 3(47): 89-96.

[8] Lago F, G'omez R, Conde J, Scotece M, G'omez-Reino JJ. Cardiometabolic comorbidities and rheumatic diseases: focus on the role of fat mass and adipokines. Arthritis Care and Research 2011; 63(8): 1083-1090. http://dx.doi.org/10.1002/acr.20488

[9] Amaro $\mathrm{F}$, et al. Insulin resistance and rheumatoid arthritis. Reumatol Clin 2011; 7(2): 124-129. http://dx.doi.org/10.1016/j.reuma.2010.03.010

[10] Castro JP, El-Atat FA, McFarlane SI, Aneja A, Sowers JR. Cardiometabolic syndrome: pathophysiology and treatment. Curr Hypertens Rep 2003; 5(5): 393-401. http://dx.doi.org/10.1007/s11906-003-0085-y

[11] Tilg $H$, Moschen AR. Adipocytokines: mediators linking adipose tissue, inflammation and immunity. Nat Rev Immunol 2006; 6(10): 772-83.

http://dx.doi.org/10.1038/nri1937

[12] Rho YH. Adipocytokines, Insulin Resistance and Coronary Atherosclerosis in Rheumatoid Arthritis. Arthritis Rheum 2010; 62(5): 1259-1264. http://dx.doi.org/10.1002/art.27376

[13] Dessein PH, Norton GR, Badenhorst M, Woodiwiss AJ, Solomon A. Rheumatoid arthritis impacts on the independent relationships between circulating adiponectin concentrations and cardiovascular metabolic risk. Mediators of Inflammation 2013; 20: 461849. http://dx.doi.org/10.1155/2013/461849

[14] Davignon J, Ganz P. Role of Endothelial Dysfunction in Atherosclerosis. Circulation 2004; 109: (23 Suppl 1): III27-32. DOI:10.1161/01.

[15] Sitia S, Tomasoni L, Atzeni F, Ambrosio G, Cordiano C, Catapano A, Tramontana S, Perticone F, Naccarato P, Camici P, Picano E, Cortigiani L, Bevilacqua M, Milazzo L, Cusi D, Barlassina C, Sarzi-Puttini P, Turiel M. From endothelial dysfunction to atherosclerosis. Autoimmunity Reviews 2010; 9: 830-834. http://dx.doi.org/10.1016/j.autrev.2010.07.016

[16] Dong JY, et al. Effect of oral L-arginine supplementation on blood pressure: a meta-analysis of randomized, double-blind, placebo-controlled trials. Am Heart J 2011; 162: 959-965. http://dx.doi.org/10.1016/j.ahj.2011.09.012

[17] Maradit-Kremers H, Crowson CS, Nicola PJ, Ballman KV, Roger VL, Jacobsen SJ. Increased unrecognized coronary heart disease and sudden deaths in rheumatoid arthritis: a population-based cohort study. Arthritis Rheum 2005; 52(2): 402-11.

http://dx.doi.org/10.1002/art.20853

[18] Amaya-Amaya J, Sarmiento-Monroy JC, Mantilla RD, Pineda-Tamayo R, Rojas-Villarraga A, Anaya JM. Novel risk factors for cardiovascular disease in rheumatoid arthritis. Immunol Res 2013; 56(2-3): 267-86. http://dx.doi.org/10.1007/s12026-013-8398-7

[19] Kerekes G, Nurmohamed MT, González-Gay MA, Seres I, Paragh G, Kardos Z, et al. Rheumatoid arthritis and metabolic syndrome. Nat Rev Rheumatol 2014; 10(11): 691-96. http://dx.doi.org/10.1038/nrrheum.2014.121
[20] Bremer AA, Devaraj S, Afify A, Jialal I. Adipose Tissue Dysregulation in Patients with Metabolic Syndrome. J Clin Endocrinol Metab 2011; 96(11): E1782-8. http://dx.doi.org/10.1210/jc.2011-1577

[21] Böger RH, Ron ES. L-Arginine improves vascular function by overcoming deleterious effects of ADMA, a novel cardiovascular risk factor. Altern Med Rev 2005; 10(1): 1423.

[22] Versari D, Daghini E, Virdis A, Ghiadoni L, Taddei S Endothelial dysfunction as a target for prevention of cardiovascular disease. Diabetes Care 2009; 32: 314-321. http://dx.doi.org/10.2337/dc09-S330

[23] He M, Liang X, He L, Wen W, Zhao S, Wen L, Liu Y, Shyy JY, Yuan Z. Endothelial dysfunction in rheumatoid arthritis. The role of monocyte chemotactic protein-1-induced protein. Arterioscler Thromb Vasc Biol 2013; 33: 1384-1391. http://dx.doi.org/10.1161/ATVBAHA.113.301490

[24] der Stoep DF VB-V, Klop B, Van Zeben D, Hazes JM, Castro Cabezas M. Cardiovascular risk in rheumatoid arthritis: how to lower the risk. Atherosclerosis 2013; 231: $163-172$.

http://dx.doi.org/10.1016/j.atherosclerosis.2013.09.006

[25] Lucotti P, Setola E, Monti LD, et al. Beneficial effects of a long-term oral L-arginine treatment added to a hypocaloric diet and exercise training program in obese, insulin-resistant type 2 diabetic patients. Am J Physiol Endocrinol Metab 2006; 291(5): 906-12.

http://dx.doi.org/10.1152/ajpendo.00002.2006

[26] Piatti PM, et al. Long term oral L-arginine administration improves peripheral and hepatic insulin sensitivity in Type 2 diabetic patients. Diabetes Care 2001; 24(5): 875-80. http://dx.doi.org/10.2337/diacare.24.5.875

[27] Cersosimo E, DeFronzo RA. Insulin resistance and endothelial dysfunction: the road map to cardiovascular diseases. Diabetes Metab Res Rev 2006; 22(6): 423-36. http://dx.doi.org/10.1002/dmrr.634

[28] Vita JA, Keaney JF Jr. Endothelial function: a barometer for cardiovascular risk? Circulation 2002; 106: 640-642.

http://dx.doi.org/10.1161/01.CIR.0000028581.07992.56

[29] Nadar S, Blann AD, Lip GY. Endothelial dysfunction: methods of assessment and application to hypertension. Curr Pharm Des 2004; 10: 3591-605. http://dx.doi.org/10.2174/1381612043382765

[30] Nakamura M, Yoshida H, Arakawa N, Saitoh S, Satoh M, Hiramori K. Effects of tumor necrosis factor-alpha on basal and stimulated endothelium-dependent vasomotion in human resistance vessel. J Cardiovasc Pharmacol 2000; 36: 48792 http://dx.doi.org/10.1097/00005344-200010000-00011

[31] Gonzalez-Gay MA, Gonzalez-Juanatey C. Inflammation and endothelial dysfunction in rheumatoid arthritis. Clin Exp Rheumatol 2006; 24(2): 115-7.

[32] Sattar N, Mccarey DW, Capell H, Mcinnes IB. Explaining how "high-grade" systemic inflammation accelerates vascular risk in rheumatoid arthritis. Circulation 2003; 108: 2957-63. http://dx.doi.org/10.1161/01.CIR.0000099844.31524.05

[33] Moncada S. Nitric oxide in the vasculature: physiology and pathophysiology. Ann N Y Acad Sci 1997; 811: 60-7. 16.

[34] Ignarro LJ. Nitric oxide: a unique endogenous signaling molecule in vascular biology. Biosci Rep 1999; 19: 51-71. http://dx.doi.org/10.1023/A:1020150124721 